\title{
Perspective of natural products in skincare
}

\section{Short communication}

According to American Academy of Dermatology (www.aad.org/ public/kids/skin), skin comprises the largest organ of human body with over 20 vital physiological functions. Skin which is a physical barrier to withstand pressure and trauma, recognize sensations and pain, protects the body from the external environment such as pollution and radiation, sunlight, keeping out harmful microbes and chemicals, and helps to regulate temperature, fluid balance and excretion, involved in endocrine function through the production of Cholecalciferol (D3) by epidermis. Skin care products are the medicinal preparations intended to be placed in contact with the various external parts of the human body that manifest beneficial topical actions and provide protection against degenerative skin conditions. ${ }^{1}$ Preparations of natural ingredients have been traditionally used for centuries for skin care purposes; nowadays they are becoming more popular in modern formulations due to consumers concerns about synthetic ingredients/ chemical substances. The use of plants for medicinal purposes is as old as humanity and plants were the main source of all personal care and cosmetics before the use of synthetic substances with similar properties. ${ }^{2}$ Additionally, the use of plant extracts in skin care products is highlighted by consumer demands, which are increasingly concerned with buying ecologically friendly products. Natural skin care products improved skin tone, texture, and appearance by delivering nutrients necessary for healthy skin. Herbal extracts are primarily added to the skincare formulations due to several associated properties such as antioxidant capacity, pigmentation inhibition, and antimicrobial activity, which can be beneficial for attenuation and prevention of various skin conditions. ${ }^{3,4}$ Cosmetics alone are not sufficient to take care of skin conditions; it requires association of active natural ingredients to repair the damage and to inhibit the ageing of the skin. Herbal skincare and cosmetics have gained much popularity and claimed to have efficacy and intrinsic acceptability due to routine use in daily life and avoid the side effects which are commonly seen in synthetic products. On the other hand, compared to synthetic skincare and cosmetic ingredients, herbal products are mild and biodegradable, exhibiting low toxicity. Natural plant molecules remain particularly interesting for new studies and a number of researches carrying in different parts of the world on medicinal plants to developed newer herbal skincare and cosmetic products having lesser side effects and rich sources of beneficial compounds. ${ }^{1,2}$ In the last few years, there has been an exponential growth in the field of herbal skincare and cosmetic products and they are gaining popularity both in developing and developed countries. Given the inherent economic potential in the exploitation of natural resources in ecosystems, plant extracts, essential oils, vegetable oils and bioactive complexes exhibit a huge potential to be used in skincare and cosmetic products in order to beautify and maintain the physiological and biochemical balance and healthy condition of the human skin.

The personal care product category remains the largest category in the beauty business and its global value sales will reach $\$ 630$ billion by 2017 . The general market demand growth rate for natural and organic skincare products alone is growing faster than the overall market growth rate. The global demand for organic personal care products is expected to reach $\$ 13.2$ billion by 2018 . Health awareness around the globe drives the natural and organic personal care product
Volume 4 Issue 3 - 2016

\author{
Mila Emerald,' Ariel Emerald, ${ }^{2}$ Leeona \\ Emerald, ${ }^{2}$ Vikas Kumar ${ }^{3}$ \\ 'Phytoceuticals InternationalTM \& Novotek Global SolutionsTM, \\ Canada \\ ${ }^{2}$ Delizioso Skincare Inc., Canada \\ ${ }^{3}$ Neuropharmacology Research Laboratory, Department of \\ Pharmaceutics, Indian Institute of Technology, India
}

Correspondence: Vikas Kumar, Neuropharmacology Research Laboratory, Department of Pharmaceutics, Indian Institute of Technology (Banaras Hindu University), India, Email vikas.phe@iitbhu.ac.in

Received: March II, 2016| Published: April 07, 2016

market, igniting a major shift from synthetic to organic personal care products. Organic personal care products in North America represented about $35 \%$ of the global organic personal market in 2014 and the natural cosmetics market hit $\$ 30$ billion last year, predicted to have an annual growth rate of $10 \%$ until 2019 . There is a noticeable increase in organic personal care products in European countries, China and India. Strong growth in distribution channels and the number of new product launches in developed as well as emerging economies is expected to trigger growth of this industry as well.

Chemicals and synthetic ingredients, used in many skincare and cosmetic products, can cause a variety of undesirable side effects, especially for people with sensitive skin and potential allergic reactions. The overwhelming array of synthetic and potentially harmful ingredients used in skincare and cosmetic products (health hazards associated phthalates, parabens, petroleum based chemicals, aluminum salts, etc.) are main reason for freshly produced organic and natural skincare, based on innovative and up to date multifunctional and effective formulations which include products with anti-aging, skin lightening and super moisturizing benefits. Large corporations are also attempting to follow the natural trend, due to consumer requirements. The most recent news is that the first time Procter and Gamble (P\&G) has published a list of 140 fragrances which they no longer use in their products, which, according to the Environmental Working Group (EWG), are linked to endocrine disruption, reproductive toxicity and cancer. ${ }^{5}$

In order to create a natural and/or organic formulation, plant derived bioactive compounds from essential oils, cold pressed vegetable oils, natural resins, extracts and other natural; raw materials are combined with plant derived emulsifiers, surfactants, humectants, pigments and other ingredients. ${ }^{6}$ Taking into consideration the huge variety of the market supply of organic plant derived ingredients which are often adulterated with synthetic or toxic intermediates. It is important to choose top quality, analytically tested ingredients from a reliable supplier, such as companies proven to follow a quality over quantity concept: Symrise, Firmenich, Citrus \& Allied Essences, 
Sabinsa, Lebermuth, Phytoceuticals International, Liberty Natural, and others. Finding a good quality sustainable source supplier with established quality assurance procedures and services, as well as clean processing, which eliminates cross contamination, is very important and is sometimes the biggest challenge for natural personal care and cosmetic companies.

A huge impact is done to the natural personal care industry by companies who purchase and use various natural and organic ingredients in their products and market the brand as 'natural', though not always containing only natural and organic ingredients. Some of those brands include but are not limited to Eminence, L'Occitane en Provence, Aveda, Burt's Bee, Organicare, Aubrey organics, Intelligent nutrients, NaturaCosméticos S.A., Beeseline, Tata Harper Skincare, Dr. Haushka Skincare, Dr. Murad Skincare, Dr. Emerald Skincare, Delizioso Skincare \& Cosmetics, Juice Beauty, 100\% Pure and many others. The quality of such marketed organic and natural personal care products is dependent on the quality of natural plant derived ingredient supply, many of which are certified by organic certification bodies such as USDA, Sanoflore, NOP, QAI and others, as well as the percentage of natural and organic content in the personal care product formula itself. UK, Germany, France, Italy and Belgium consolidated the regulations under COSMOS (one regulatory body). In Japan, cosmeceuticals are regulated as quasi-drugs. ${ }^{7}$ Organic and Sustainable Industry Standards (OASIS) 'made with organic' must contain $70 \%$ minimum organic content, while organic requires $85 \%$, but the requirement increased $95 \%$ in 2012. According to a new obtained standard, the Natural Products Association (NPA) recognize product as natural only if it contains minimum of $95 \%$ of ingredients from natural sources. ${ }^{8-10}$ There is strong trend for regulation and proper testing of the natural and organic personal care products which is expected to ensure the quality, properties and corresponding shelf life. ${ }^{11}$

In spite of the availability of excellent quality natural plant derived ingredients, manufacturers of organic personal care products are still facing some serious challenges. Microbial contamination in personal care, skincare and cosmetic products lead to instability such as product separation, discoloration, and formation of gasses and odors. Non-availability of the proper type of natural preservatives effective for all the spectrum of the microorganisms (gram positive and gram negative), fungus and viruses, which can guarantee a prolonged shelf life without toxic side effects is one of the most challenging problems which natural personal care products face. Natural personal care products are often made in large batches and stand in storage and/or shelves for an extended period of time prior to reaching the end consumer, which can therefore lead the product to contain higher concentrations of microorganisms if not properly preserved. This is why many consumers prefer freshly 'made to order' products when choosing natural personal care. Some companies that market their products as freshly made to order include but are not limited to: Lush Cosmetics, Delizioso Skincare, Beeseline and Dr. Emerald Skincare.

The nutricosmetic companies (Perricone, Borba, Glowelle, and others) which combine diet supplements and nutritional support routine along with skin care products containing vitamins, fatty acids, hyaluronic acid, alpha-lipoic acid and bio active botanicals are oriented for a great systemic result, better health and beauty, promote youthfulness by targeting and reversing specific physiological and cellular processes leading to premature aging. Bio botanicals usually include ingredients promoting skin health, have anti-inflammatory properties and promote circulation, cellular vitality and regenerative mechanisms. The Natural Marketing Institute (NMI) report published in 2007 demonstrated that personal natural products segment is also exponentially growing for men, and also includes a cosmeceutical range. ${ }^{12}$ There are quite a few natural skincare brands for men who contain great plant derived ingredients, such as RSVP's, Bulldog, Intelligent Nutrients, Naturopathica, Weleda, Jack Black, Dr. Emerald Skincare for men, Dr. Bronners products, and others. There is also a significant trend in natural products for babies, which includes bath and body care products, as well as skin actives and sunscreens. ${ }^{11}$

There is a large international demand for the development of anti-aging, UV protective, whitening and extra moisturizing natural skincare products. The anti-aging skin care products trend is moving towards developing new botanical ingredients and intermediates targeting specific needs, based on discoveries, and advanced technologies. ${ }^{13}$ In case of anti aging products, the age-related decline in skin regenerative cells is a result of homeostatic imbalance, cutaneous disorders, environmental factors. ${ }^{14,15}$ Skin exposure to UV radiations cause oxidative stress, inflammation, wrinkling, skin cancer, erythema, edema, sunburn and photoaging ${ }^{16}$ and can lead to generation of toxic compounds and reactive free radicals, which can cause damages to DNA in nuclei and mitochondria, deterioration of membranes, lipids and proteins in skin-resident stem/progenitor and following cell dysfunctions. ${ }^{11,18}$ There are quite a few natural compounds, which can prevent from UV damage: $\alpha$-tocopherol which prevents UVAand UVB-induced glutathione loss and reduce induction of DNA damage by UVB. ${ }^{19,20} \beta$-Carotene which inhibits free radicals and cause higher resistance to immunosuppression after exposure to UV light; ${ }^{21}$ lycopene which absorb light in the UV range and increase the toughness of the skin. ${ }^{22,23}$ Lutein which prevent extracellular matrix breakdown and prevents skin from UV damage; ${ }^{24}$ flavonoids such as isorhamnetin, quercetin, kaempferol which significantly decreased erythema developed after UVB irradiation, ${ }^{25}$ and green tea polyphenols which reduce UV-induced 533 expression and keratinocytes apoptosis and protect from DNA damage, ${ }^{26}$ and others. Among the other natural plant derived compounds, polyphenols (for example from green and black tea) are shown to promote the degradation of melanin causing depigmentation effect on animal skin in vitro. ${ }^{24}$

The research challenges in natural personal products trend are including creation of a perfect ratio between the natural plant derived ingredients and bio actives, which will provide great product absorption, proper moisture balance, effective and improved cellular metabolism including hormonal and chemical skin reactions, efficient hydration, proper exfoliation, effective circulation and cellular nutritional support, enhanced lymphatic functions and detoxification of the skin.

There are no doubts that global natural and organic personal care products market is growing, significantly expanding and by Grand View research Inc, is expected to reach USD 15.98 billion by $2020 .{ }^{27}$ North American and International companies are undertaking strategic initiatives to increase presence and percentage of the natural skincare and cosmetic products on the Global market. Instead of synthetic products, North American and International consumers prefer organic and natural non toxic and environment friendly personal care products which definitely represent the major stream in personal care and cosmetic industry. 


\section{Acknowledgements}

None.

\section{Conflict of interest}

The author declares no conflict of interest.

\section{References}

1. Ribeiro AS, Estanqueiro M, Oliveira MB, et al. Main benefits and applicability of plant extracts in skin care products. Cosmetics. 2015;2(2):48-65.

2. Fatima A, Alok S, Agarwal P, et al. Benefits of herbal extracts in cosmetics: a review. Int J Pharm Sci Res. 2013;4(10):3746-3760.

3. Fowler JF Jr, Woolery-Lloyd H, Waldorf H, et al. Innovations in natural ingredients and their use in skin care. J Drugs Dermatol. 2010;9(6):S72S81.

4. Ribeiro AS, Estanqueiro M, Oliveira MB, et al. Main benefits and applicability of plant extracts in skin care products. Cosmetics. 2015;2(2):48-65.

5. Cosmetic Business. In: Cosmetic Business News; 2016

6. Chiu A, Kimball AB. Topical vitamins, minerals and botanical ingredients as modulators of environmental and chronological skin damage. $\mathrm{Br} \mathrm{J}$ Dermatol. 2003;149(4):681-691.

7. Steinberg DC. Cosmeceutical regulations: A global overview. Cosmetics and Toiletries. 2005;120(2):32-34.

8. Corley JW. Natural and Organic: The Emerging Revolution. In: Lawrence BM. Natural and Organics in Cosmetics: From R and D to the Marketplace. USA: Allured Publishing Corporation; 2007. p. 55-66.

9. Matthews I. Naturals hit mainstream. In: Lawrence BM. Natural and Organics in Cosmetics: From $R$ and D to the Marketplace. USA: Allured Publishing Corporation; 2007. p. 17-20.

10. Whittaker MH, Engimann E, Sambrook I. Eco-labels: Environmental marketing in the beauty industry. Global Cosmetic Industry. 2009;77:3034.

11. Abedon B. Consumers seeking nutricosmetics with multifunctional benefits. Las Vegas: West International Trade Show and Conference; 2009 $7-8$.

12. Alford B, Hoffman J. Skin care brand focuses on male luxury consumers. Global Cosmetic Industry. 2008;176:64.

13. Roehl EL. Consumption. In: EU Market Survey 2000: Natural Ingredients for Cosmetics. Compiled for, CBI, center for promotion of imports from developing countries. 2000;2:13-16.
14. Sharpless NE, DePinho RA. How stem cells age and why this makes us grow old. Nat Rev Mol Cell Biol. 2007;8(9):703-713.

15. McCullough JL, Kelly KM. Prevention and treatment of skin aging. Ann N Y Acad Sci. 2006;1067:323-331.

16. Iddamalgoda A, Le QT, Ito $\mathrm{K}$, et al. Mast cell tryptase and photoaging: possible involvement in the degradation of extra cellular matrix and basement membrane proteins. Arch Dermatol Res. 2008;300:S69-S76.

17. Pillai S, Oresajo C, Hayward J. Ultraviolet radiation and skin aging: roles of reactive oxygen species, inflammation and protease activation, and strategies for prevention of inflammation-induced matrix degradation - a review. Int J Cosmet Sci. 2005;27(1):17-34.

18. Kwon OS, Yoo HG, Han JH, et al. Photoaging-associated changes in epidermal proliferative cell fractions in vivo. Arch Dermatol Res. 2008;300(1):47-52.

19. Henegouwen GM, Junginger HE, de Vries H. Hydrolysis of RRRalphatocopheryl acetate (vitamin E acetate) in the skin and its UV protecting activity (an in vivo study with the rat). $J$ Photochem Photobiol B. 1995;29(1):45-51.

20. Chen W, Barthelman M, Martinez J, et al. Inhibition of cyclobutane pyrimidine dimer formation in epidermal $\mathrm{p} 53$ gene of UV-irradiated mice by alpha-tocopherol. Nutr Cancer. 1997;29(3):205-211.

21. Wertz K, Hunziker PB, Seifert N, et al. beta-Carotene interferes with ultraviolet light A-induced gene expression by multiple pathways. $J$ Invest Dermatol. 2005;124(2):428-434

22. Di Mascio P, Kaiser S, Sies H. Lycopene as the most efficient biological carotenoid singlet oxygen quencher. Arch Biochem Biophys. 1989;274(2):532-538

23. Darvin M, Patzelt A, Gehse S, et al. Cutaneous concentration of lycopene correlates significantly with the roughness of the skin. Eur J Pharm Biopharm. 2008;69(3):943-947.

24. O'Connor I, O'Brien N. Modulation of UVA light-induced oxidative stress by beta-carotene, lutein and astaxanthin in cultured fibroblasts. $J$ Dermatol Sci. 1998;16(3):226-230.

25. Aquino R, Morelli S, Tomaino A, et al. Antioxidant and photoprotective activity of a crude extract of Culcitiumreflexum H.B.K. leaves and their major flavonoids. J Ethnopharmacol. 2002;79(2):183-191.

26. Yusef N, Irby C, Katiyar SK, et al. Photoprotective effects of green tea polyphenol. Photodermatol Photoimmunol Photomed. 2007;23(1):48-56.

27. Organic personal care market analysis by product (Skin Care, Hair Care, Oral Care, Cosmetics) and segment forecasts to 2020. San Francisco, USA: Grand View Research Inc; 2015. 